\title{
The Professional Pedagogy Helping Adults in the Couple, Family and Parenthood Situations
}

\author{
Franco Blezza \\ Full professor \\ General and Social Pedagogy \\ DPPEQ “Gabriele d’Annunzio” University \\ Chieti and Pescara, Italy \\ Email: franco.blezza@unich.it \\ Italy
}

\section{ABSTRACT}

The pedagogical interlocution is a specific technique of professional-pedagogical practice in the form of dialogue that we used to support couples and families. This paper is an overview of the broader and more comprehensive case studies, we dealt with, providing an account that we think significant for the professional pedagogist's role and function.

\section{KEYWORDS: Pedagogist, social professions, Sozialpädagogik, helping relation, family}

\section{Introduction and aim}

This concise writing aims to provide a brief example and a testimony of the pedagogist's peculiar way of professional practicing for the couples, about parenthood, which is quite often accompanied by problems related to the partnership. These problems are reflected in the children, may have different symptoms right in the same children.

We will refer to those particular circumstances that show their essential problematic core in both the contractors within the couple and that have been the subject of our pedagogy-based intervention to support them. We feel the need to underline one of the necessary conceptual shifts that occur nowadays and that consists of not misinterpreting the pairs with the family, thus making each of them a separate topic of study and intervention, although not so distinguished and apart. Problems in the partnership are often the objects of some deceptive attempts to seemingly simple solutions in parenthood: examples can be found in children's manipulation, or in the plan to solve actual problematic events by a future birth.

\section{Methods and conceptual and operational tools: the pedagogical interlocution}

To deal with the issue of such a domain with conceptual and operational tools, specifically pedagogical, we will refer to the so-called "pedagogical interlocution". This is a form of dialogue and consists of a set of procedures to help a person, even if she/he is part of a couple or a family, through an intervention on her/him. Moreover, the pedagogical interlocution is also a special paradigmatic form of the oriented helping relationship, through which it is possible to implement the methods, the conceptual and operational tools and specifications of the social and professional pedagogy. Experiences in this field regarded mostly couple and partnership problems, even in parenthood and its consequences on children, as previously claimed. We could consider this method as a way to help the children while helping their parents.

Pretending not to stay behind the details of the mentioned procedure and sending any further investigation back to the volumes quoted in reference, we will briefly highlight some key features, some pivotal traits, which are worth to its usefulness and feasibility, in regards to the starting problems.

We assume that in this context one can talk neither of "users" nor of "clients" or "patients", this last word resulting wrong since the function of the pedagogist is not dealing with therapy owing to intrinsic culture-based reasons belonging to her/his way to perform and practice. Rather one can properly define them as "interlocutors".

They introduce themselves by presenting what they call "problems", that actually are "problematic situations" which every human being physiologically lives in relation with the environment, meant in a cultural sense, as well as all the situations of conflict, lack of balance, opposition, discrepancy, difficulty, conflict and whatsoever alike. The first task of the pedagogist in 
the process of interlocution is to pull the interlocutor himself toward the transition from that sort of situation to problem posing. To do this the subject is elicited by processing the problematic situations felt as such and choosing among the ones he/she is ready to face with a positive and constructive response. In a word, she/he is willing to address her/his voluntary effort to solve them through a guided process. If problematic situations occur, men, themselves can pose problems.

The parental couples often attribute problematic situations to their children. But problems sometimes have to be looked for in the parental relation, or one of the two partners. Even the shift in the solving attitude to move the interlocutors from a situation where the most acute symptoms occurred, therefore, believed problematic, to the place where unsuspiciously the real problem lies is a big step forward. This is a challenge the pedagogist cannot resign, besides testing her/his competence. This is even truer if the problematic situations that arise in children are the same that forced the two parents or just one of them to ask the pedagogist for helping and professional support.

The pedagogist however, never offers any solution to people who are asking for it, rather once the persons have posed the problem, they are helped by her/him to discover their own. And these are not believed to be the same as for any other human beings under the same circumstances. Here comes into play the practice of that highest human faculty which is creativity, to whose activation and development, the pedagogist's role we maintain, is of paramount importance. Nevertheless, she/he will mind some provisions and rules to fulfill her/his profitable human and social role.

Practicing creativity is a rule-directed activity; we must if anything, see, from time to time, the set of provisions and rules that make it productive, under a human sense. As in the Western world the romantic myth of "genius and lack of rules" fulfills a historical, social, cultural function, and as a matter of fact, everyone is consistent with some laws or rules while creating, first of all, the "genii". It is important to understand, from time to time, which set of rules they, to begin with, the last ones mentioned, apply to their creative act.

As for the pedagogist's professional help, we can consider an advanced epistemology, i.e. that which stretches from the classical Pragmatism to Critical Rationalism, Neo-Pragmatism and other theories developed in the XX century, a very useful scientific and cultural background, after it has shown, among other things, even to our experience and its adequacy. We recall the most important and relevant orders of methodological laws or rules to be observed in this respect:

$>$ the "internal" coherence, that is to say ${ }_{2}$ the respect of logical provisions, belonging either to classical firstorder logic or to any alternative of the latest historical suggestion;

$>$ the "external" coherence, that is testing by facts, the organic and systematic relationship between ideas, projects and assumptions on one hand, and the event of education and social relations on the other: in our case, the event of the couple and possibly the family. We know that the experience, called by the pragmatists "future experience", can provide falsification, but with no terms verification; at least what in the XXth century has been referred to in a weaker sense as "corroboration";

$>$ the sense of "historicity", i.e. to give life to our ideas, our choices, projects, positions through the temporal becoming of the environment, society and those who, in a way, is closer to us;

$>$ the sense of criticism on which one could open an endless discussion, however, not to be confused with the search for systematic contradiction;

$>$ ideas are for men, never the opposite.

Also, because of these considerations, we should never forget that among the fundamental skills of the social and professional pedagogy, especially as far as such a professional practice regards, the methodological expertise comes out.

The pedagogist expresses no judgments, nor decisions; she/he does not state requirements, and to be strict, she/he doesn't give any sort of advice. Instead, she/he offers opinions, directions, points of view, alternatives, suggestions, to turn into objects of a dialogue based on critical analysis. She/he is a part of this process and, as such, he can also suggest her/his personal view 
and life experience: but she/he can just do that if the interlocutor is not misinterpreting as privileged, her/his statements, as rules to be followed, being uttered by an expert. Each suggestion is a possible topic of discussion.

To use the adjective "questionable", "controversial", is deprived of the smallest negative connotation, it is rather a sign which shows us the pedagogical frame is properly caught. If one suspected to say or suggest something "indisputable", the talk would not be about pedagogy. The pedagogy culture in use is that the practitioner should always mind the fallibility and the everlasting search, which are closely linked to the lack of omnipotence of this, as of any educational intervention.

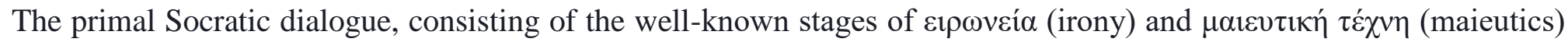
could have a conclusion since it allowed to achieve $\alpha \lambda \eta \dot{\eta} \theta \varepsilon \alpha$ (some truths, is the translation of these words in its approximate value) in this second stage. The pedagogical interlocution has, instead, no virtual end. It may present, and it is nourished by some breaks, nevertheless aiming at a future expansion and an endless recurrence.

Interruptions not only exist as factual opportunities, but they are meant to be a rightful prediction before any pedagogical interlocution begins. This particular supportive relationship must be limited in time, and under this respect, it is quite different from the traditional psychotherapy, as well as any teaching or physical training relationship. We have been voluntarily producing such different examples, which testify the presence of neighboring professionals to the pedagogist.

The need to keep the pedagogical interlocution limited in time, comes first conceptually from the awareness that education is not omnipotent. In terms of professional practice, such a need derives from the fact that the pedagogist uses die Einfühlung, systematically. It is a peculiar form of empathy enacted voluntary; it is both taught and learned and can be summarized as a catching into the problematic situations belonging to the interlocutors when they turned to the professional pedagogist, so that she/he can return them in better problem-posing and problem-solving forms.

At any extent, she/he never has to hope to keep the situation under control, even in this specific regard. Such a conclusion prevents him/her from feasible wear and tear which would make him/her unfit to perform her/his work.

This does not mean, of course, to leave the interlocutor alone: it is, therefore, possible to address two different forms of redirection supposed to be the continuum of the pedagogist's activity.

The first is defined as "canonical re-direction", that means an invitation to go on with the dialogue whenever the problems have been posted, or more likely, whenever the problematic situations have been shown either in the couple or in the family or about both human associations.

This event is considered, in general, more desirable.

The second is called "professional re-direction", and implies the need or, at least, the chance to keep the discussion alive with another professional, paying the utmost attention not to point out just the professional's specific nature to talk with, but above all, whenever any need arises, to create the best conditions to keep on in this direction, inspiring the interlocutor's confidence toward the next professional relationship and removing, as far as possible, any prejudices against this or that practitioner. We are fully aware that psychologists, as well as social workers, lawmen, many medical specialists, etc. are carrying a burden on their shoulders which is, by no means, light, although being overcome.

In these last cases, the pedagogist acts essentially as a teacher, performing particular informal teaching. It is up to her/him to remove this sort of barrier.

\section{Case studies of couples and parenthood dealt with: a broad outline}

The case studies we dealt by the pedagogical interlocution are of a wide variety, and always refer to "persons" in the technical sense of the term, which does not mean that we cannot bring them to a relatively small number of cases or "casuistries", as they are called with a specific additional term. The profession would not exist without specificity. Such an arrangement requires the human being practitioner's mediation, as in the particular case of abduction as taught by Charles S. Peirce.

We faced with cases which, as previously stated, have their core problems within the couple or in each of the two partners, but which are quite often attributed to children, showing consequences, symptoms, worrisome phenomenology involving the urgent need to turn to the professional and social pedagogist's expertise. The adoption of the clinic-case study (casuistry) method 
is in response to a purely qualitative sensitivity, and without excluding in advance a possible integration with quantitative methods, what we are going to do in this context, is simply to draw some examples, with no claim of regularity.

I. A first general casuistry (case-study) that refers to similar ones which have in common some lines of action concern the existence in each of the two partners of life projects mutually conflicting and contradictory, they have always been inconsistent, from the very beginning, but never explained as such. This is a clear violation of the "internal" coherence rules. They are serious contradictions and ultimately difficult to repair that has been kept hidden for years and decades, having the two partners been discussing many things before and after being committed in the couple, but often ignoring key issues, such as children (if to have children or not, how many, when, under which circumstances...), his and her work arrangements, the balance between home and social commitment and between the public and working commitment of each of them; and the possible evolutions of those arrangements whose balance sometimes may be inherently problematic.

The same home management and how to share the tasks, the social role management and its relational nature are sometimes neglected or even ignored. They go on debating for months how to set the wedding up, the ceremony, as for example the Church decoration, the clothes and the hairstyles to wear: external hyperbolic forms, the "honeymoon trip" included. We understand here there is nothing unconscious: a great amount of issues is, on the contrary, conscious yet hidden, not well addressed, unspoken, covered by the partners' comforting beliefs that lack real feedback (violation of "external" coherence rules).

II. Significantly different is the casuistry of the two partners' life projects which at first did not show substantial contradictions, considered therefore consistent, yet becoming divergent and even conflicting as time went by in this case ${ }_{2}$ one often neglects to observe the rule of "historicity". How many women partner feel the need, when they are around 30 or 40 or even older, for a professional, cultural, social commitment as volunteers or in associations and cooperation or alike; they feel the need to spend their abilities, once exclusively believed to be expressed within the couple, out of it, out of their home or family. Sometimes they call the young children into question, but kids grow up. Here the problem is not to sacrifice herself for some time, first of all, because of historical evolution, then because this deals with renouncing to those unavailable goods as all the other which make a human being a person endowed with her/his own rights.

The result is that when and if one of the partners asks for the coupling structure to be changed, the other often reacts negatively and indeed with an emotional charge or with. He, however, has no right to refuse such a renegotiation being in a totally wrong position, misconduct that is meant to interfere with the beginning of his partner's external investment, an investment that for a long time was neglected or shaped in the couple itself.

III. In case studies, like these, a great part is played by the dangerous and troublesome idea according to which creating the couple and contracting marriage, instead of being the start of a social commitment, in terms of a mutual respect for other people and the whole society, is rather a "happy ending" and a final conquest. If fairy tales once ended with the closing ritual "and they lived Joyfully and happily ever after", we easily understand the educational reasons and the psychological perspectives which inspire it, especially after Bruno Bettelheim's teaching. Nevertheless, we should understand either its scanty value for the couple's future life, in terms of what kind of life the couple would be able to live soon after such an important transition, with reference to family and parenthood. The issue is, in a word, a "time bomb", neither necessarily the result of unconsciousness nor shallowness.

The fact is that the creation of a pair and then of a family has a euphoric effect, filled with enthusiasm and responsibility that leads the contracting parties to develop, quite often, a tendency to soften everything and that does not allow to see the overt problems. It is even worse when those problems would require a recognition within the domains of the single life projects whose discussion and dissection with the other are believed not necessary at all. Such an escape from the couple's problems is strengthened by some out of fashion social behaviors, nowadays empty of an intrinsic meaning, yet life-long routinized, and even by the most grotesque and overstated nonsense of the ceremony, with all its bells and whistles (among other things excessively expensive), and its unconditioned cheers. The wedding is always "right", despite everything and to get married is always referred to with the funny expression "to tie the knot". In Italian, it's commonly said "convolare a giuste nozze". 
IV. That euphoric effect and that new energy could be valuable if it were invested outside, in order to put the couple in the best conditions to raise a future family, whereas, most of the times, it is given and segregated inside, burnt in the partnership, lessening the precious human and sometimes instrumental resources till their end, diminishing the couple's ability to solve problems, such as work, social problems or even to take care of their children.

What we are going to describe is not true love, despite what the two in the couple think for themselves or show to the other people: love is true when it endows the man and woman acting each outside the couple, helping one another; when love is spread around, outside and inside, making the two people aware of themselves in a life-long training process, never diminishing and never satisfied.

V. A limit casuistry is presented by Erich Fromm as a criticism to Harry Stack Sullivan's theory: the consumeristic and closed love is not true love, rather it is a form of mutual selfishness that, as such, should be helped to be overcome, and in some severe cases, submitted to therapy.

More generally, such a serious lack of dialogue is found before the couple is transformed into a family, having some negative and often dramatic consequences on the pivotal aspects of the pair's life, as time goes by.

To distort the perspective, the sense of fatalism combines with the complex of privacy hypocritical coverage, domesticity, respectability and so forth, which occurred in the eight - ninth century nuclear family. As this coverage fell down, some problems of unprecedented severity were unveiled, once and for a long time being compressed within the four walls, behind the door and the drawn curtains. It is told, as a matter of fact, with no discrimination, "don't wash your dirty linen in public", in Italian "I panni sporchi si lavano in famiglia", to mean that what is wrong in the family must not be shown outside, but solved inside the family itself. This principle could be interesting, but it does not allow us to see if someone really cleans the linen imbrued by someone else, or if that line becomes "dirty and dirty", that is to say, if the balance of such a family is in the same person who usually clean what the other one usually imbrues. The image seems significant.

VI. A further casuistry dwells on the lack of consideration, otherwise the erroneous consideration, of how the structure of the couple is changing when pregnancy begins and later with childbirth. Sometimes the smallest necessary change is neither even taken into account, nor properly considered. Also, sometimes everything seems taken for granted as if those steps were required (actually, not required at all!), thus acknowledging life in pair seriously compromised. This is what happens when the problems concerning parenthood are not have been mutually dealt with. Such problems belong therefore to parents and not to children.

It should be stressed here that the pedagogic support can be given only when it is required; there is no official pedagogical intervention, least of all in all the circumstances belonging to the couple.

On the other hand, in Italy, there are cases provided for by law in which there are compulsory medical surgical authorities, or social workers, for example.

VII. In order to introduce another casuistry, we must refer, from a critical point of view to the phenomenon denounced in Italy: sons and daughters who are thirty or older who live with their parents. The case is of sons who do not want to go away and be autonomous; someone calls them "babes in the woods" or Peter Pan. This, of course, is a problem but also an integration to a family separate case study.

It is different from the casuistry of the family where one or more sons, at a certain time, really go away. They acquire autonomy both in the job and in society, with or without living in a couple. This is referred to by someone with an obvious, misleading and unpractical wordplay, the" empty nest syndrome". One talks in such a way as if the nest existed not to be left empty, as if the son or daughter who is going away from home did not take note of the canonical development of parenthood. The problem, however, is different and, once again, it goes back to the couple's structure. To the son, the partner can be substituted. Each of the partners who are suffering from this circumstance of "emptiness" makes us think of some problems in the partnership which have not been dealt with for a long time.

The support to give in such a case is great, in order that the spouses regain a relationship where a son or a daughter does not admit any replacement. 
The ways to manipulate children by one parent against the other are so many as for number and variety that here we can just draw our colleagues' attention on them. A child is often aimed at regaining personal identity, to feel a full man or woman, to tie, to blackmail the partner; a child to be put on the bridal thamlamous in order to refuse the partner's sexual approach.

In cases like these, and in many other similar ones, there is a general warning to follow: never discuss the reason, the goal, since you can always find a noble and a sounding goal for manipulating, especially against a person in need and not autonomous. The goal should not be discussed, because using a human being as a tool is always an inadmissible, incoherent human action, besides having no justification. We appreciate and respect those who strive upward; but no one, in any circumstance or hypothesis is entitled to use another human being for any reason, even less here/his son or daughter.

They need their parents' help, they have the right to be supported, being from a pedagogical perspective not tools in any case.

\section{Discussion, and conclusion: the apology of the dialogue}

The speech could go on and on. The examples showed, and primarily referred to adults in couples, with or without issue, subjects of our specific experience and treated through pedagogical interlocution, remind us of some necessary reflections. The first is that, on one hand, there is a growing need for people to regain a context where communication is placed as an intentional act, on the other the lack to establish personal interactions aimed at sharing not only signs but most of all meanings.

Summarizing the professional experience reported here, most of the times it is as if we were witnessing an erosion of the forms of the words which refer to separate universes, not to a mutual feeling, to distant perceptions, inconsistent interpretations of life experiences: perspectives that put the addresser far away from the addressee, instead of merging them into a unique whole. Time, lifestyles, working commitment, the same "liquid" society, prejudices, false ideas, stereotypes are not in favor of those elements which enrich the process of communication and which are the glue for the couple. If some personal variables are added, such as to be unable to change one's own mind, one's own personal opinions, we cannot deny being in front of an essential pedagogical problem.

Teaching dialogue to adults in a couple means first of all giving them an example through interlocution. Building the ground for a common, empathic way to feel, means to practice with each one or both of them the sense of care, of respect, of responsibility for problems. Fostering them to be opened outside means let them live an attitude of availability, by taking a problematic situation in charge, besides showing them the pleasure to achieve joined gains, from problem finding to problem posing and solving. As our professional evidence-based experience shows, we believe that the character of the pedagogic practitioner, primus inter pares in such a context, can play the role of a process mediator, through the powerful medium of the dialogue, forever potentially "inconclusive", i.e. never-ending. She/he can, simply and humbly, try to foster, promote, encourage, improve the relationships of human beings and through communication, never forgetting the basic principle by Descartes, according to which "One could not learn and acquire better as by discovering on her/his own".

\section{REFERENCES}

Ariès, P.; Duby, G. (responsables d'ensemble) (1985-1987) Histoire de la vie privée (5 tomes), Paris, Éditions du Seuil. Bartley III, W.W. (ed.) (1982-1983) Postscript to the Logic of Scientific Discovery by Karl R. Popper, 3 voll., London, Hutchinson. Blezza, F. (2001-n. e. 2011) Pedagogia della vita quotidiana -La formazione del pedagogista professionale, un aiuto per chiunque sia educatore. Cosenza, Luigi Pellegrini.

Blezza, F. (2005, n. e. 2010) La pedagogia sociale - Che cos'è, di che cosa si occupa, quali strumenti impiega. Napoli, Liguori. Blezza, F. (2018): Pedagogia professionale - Che cos'è, quali strumenti impiega e come si esercita. Limena PD, Libreria Universitaria.

Borrelli, M.; Ruhloff, J. (ed.) (1993-1996-1998) Deutsche Gegenwartspädagogik, Band 1, 2, 3, Baltsmannweiler Schneider Verlag Hohengeren. 
E-ISSN: 2469-6501

VOL: 5, ISSUE: 12

December/2019

CPER

DOl:10.33642/ijbass.v5n12p1

https://ijbassnet.com/

(C) Center for Promoting Education and Research (CPER) USA

www.cpernet.org

Catarsi, E. et Portois, J.P. (ed.) (2011) Educazione familiare e servizi per l'infanzia - Éducation familiale et services pour l'enfance. Firenze, Firenze University Press.

Crispiani, P. (2001) Pedagogia clinica - La pedagogia sul campo, tra scienza e professione. Bergamo, Junior.

Crispiani, P. e Giaconi C. (2015) Hermes 2016 - Glossario pedagogico professionale. Junior, Bergamo.

Dewey, J. (1938) Logic: The Theory of Inquiry, New York, Henry Holt and Company.

Duby, G.; Perrot, M. (responsables d' ensemble) (1990-1991) Histoire des femmes en Occident, 5 volumes, Paris, Pion.

Fromm, E. (1956) The art of loving, New York, Harper \& Row.

Hartshorne, C.; Weiss, P.; Burks, A.W. (eds.) (1931-1958) Collected Papers of Charles Sanders Peirce, 8 vols., Cambridge, Massachusetts, Harvard University Press.

Iori, V. (ed,) (2018)

Lapassade, G. (1971) L'autogestion pédagogique, Paris, Gauthier Villars.

Telleri, F. (e,) (2006) Consulenza e mediazione pedagogica con materiale multimediale, Sassari, Carlo Delfino editore.

James, W. The principles of Psychology 2 vols., New York, Henry Holt and Co., 1890.

Popper, K.R. Logik der Forschung (impressum 1935, tatsächlich 1934). Wien Springer-Verlag.

Rogers, C. (1951) Client-Centred Therapy: Its Current Practice, Implications and Theory, London, Constable. 